\title{
El humor político clandestino. ¿La crítica más temida de todo régimen?
}

\section{Resenha da obra:}

VÁRNAGY, Tomás: “Proletarios de todos los países... ‘Perdonadnos!” El humor político clandestino en los regímenes de tipo soviético y el papel deslegitimador del chiste en Europa central y oriental (1917-1991). Buenos Aires: EUDEBA (Editorial Universitaria de Buenos Aires), 2016. 372 páginas.

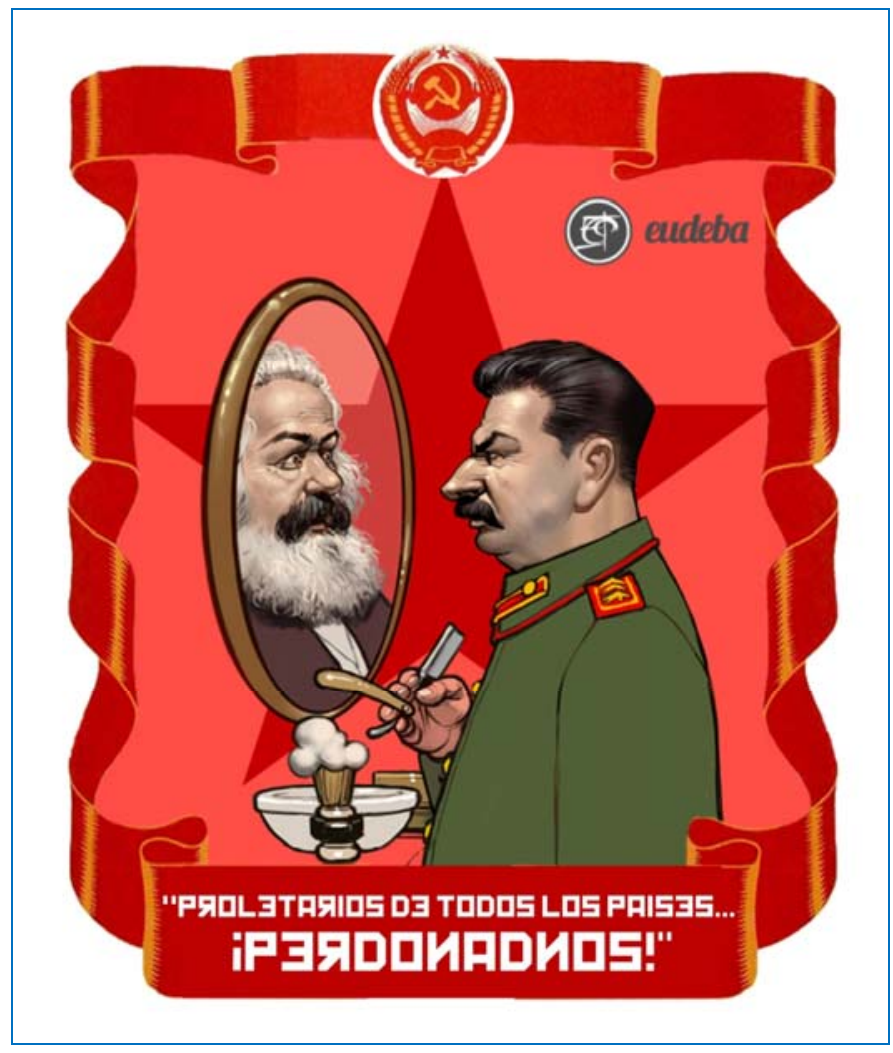

\section{Autor da resenha}

Diego Hernando Gómez

Sociologo e historiador de la Universidad de Buenos Aires (UBA). Trabajo en la Universidad del Salvador y ETER. Argentina rodia85@hotmail.com

\section{Para citar esta resenha:}

GÓMEZ, Diego Hernando. El humor político clandestino. ¿La crítica más temida de todo régimen? Revista Tempo e Argumento, Florianópolis, v. 8, n. 18, p. 445 - 450. maio/abr. 2016.

DOI: $10.5965 / 2175180308182016445$

http://dx.doi.org/10.5965/2175180308182016445 
Este libro es una mordaz y corrosiva crítica de los "socialismos realmente existentes" en Europa. El autor, de izquierdas y admirador del pensamiento de Karl Marx, aclara en el Prólogo (pp. 7 a 11) su postura en contra del capitalismo depredador, el imperialismo y la política exterior de los Estados Unidos. Su hipótesis central, “exagerando y a la manera de un chiste" (p. 359), es que la caída del Muro de Berlín y la implosión de la Unión Soviética no fueron provocados por la política del Papa Wojtyla, ni los muyahidines de Afganistán, ni la Guerra de las Galaxias de Ronald Reagan, tampoco Gorbachov o la ineficiencia del sistema soviético, sino que fueron incitados por los chistes y el humor clandestino.

En la Introducción (pp. 13 a 24), cita a Bertolt Brecht: "No se debe combatir a los dictadores, hay que ridiculizarlos", y cuenta que comenzó a coleccionar chistes sistemáticamente luego de leer un libro de Agnes Heller, Ferenc Fehér y György Márkus (discípulos de György [Georg] Lukács de la Escuela de Budapest) en el cual se narra el siguiente:

Un día Stalin hizo comparecer a Radek, que era bien conocido por su cinismo y dado a decir cosas que otros ni siquiera se atrevían a pensar. Stalin le dijo: Me han informado, camarada Radek, que te expresas de mí de un modo irónico. ¿Has olvidado que soy el líder del proletariado del mundo?

Discúlpame, camarada Stalin - replicó Radek -, ese chiste en particular no lo inventé yo.

Existe un debate sobre la naturaleza paradojal del humor, y la pregunta que trata de responder el autor es si los chistes políticos clandestinos (prohibidos) en los regímenes de tipo soviético fueron efectivamente un factor de deslegitimación o tuvieron un papel inoperante y nulo. Su hipótesis es que los chistes efectivamente pesaron en el proceso de deslegitimación política de estos regímenes, desestructurando y poniendo "patas arriba" el orden establecido.

Los chistes hacían constante referencia a la brecha entre la propaganda y la realidad concreta, reflejando una doble vida que diferenciaba claramente lo público de lo doméstico. Con esos chistes, se pretendía mostrar las incongruencias y distorsiones en un mundo dicotómico entre la ideología oficial dominante y las circunstancias materiales 
reales, produciendo una risa liberadora de las constricciones, pues se revelaban las contradicciones entre ambas esferas.

En el primer capítulo, “Teorías del humor” (pp. 25 a 69), se hace un análisis acerca de las teorías del humor, la risa y el chiste, mostrando las diferentes perspectivas que resultan en casi un centenar de teorías documentadas con respecto al tema. El autor aborda la historia del pensamiento occidental, desde el Antiguo Testamento y los Evangelios, pasando por la risa homérica, las comedias de Aristófanes y la filosofía griega, tanto Platón como Aristóteles. También analiza la "seriedad oficial” medieval, el pensamiento de Tomás de Aquino, la interpretación de Humberto Eco en El nombre de la rosa y el Carnaval del Medioevo, que producía un "mundo al revés" en donde la risa de los campesinos era una revuelta en contra de todo lo establecido.

Thomas Hobbes desarrolló la teoría de la superioridad, comenzada por Platón, afirmando que la risa es de los poderosos. Con Immanuel Kant, apareció la teoría de la incongruencia, pues lo que provoca risa tiene que ver con una expectativa que queda en la nada. Herbert Spencer consideró a la risa como un desahogo de energía y Sigmund Freud retomó esta teoría de la descarga, discurriendo que el humor y los chistes son un alivio que permite la expresión de tensiones sexuales y agresivas de una manera socialmente aceptable.

En el segundo capítulo, "Humor político" (pp.71 a 111), Várnagy, desde una perspectiva general, considera que los chistes expresan concentradamente eventos sociales y políticos, dando cuenta del humor político en la Antigüedad y el Medioevo y, con la invención de la imprenta y la lucha entre católicos y protestantes, muestra el surgimiento de toda una corriente de chistes anticlericales. El humor político podía ser peligroso - Daniel Defoe fue a la picota por su parodia de los Tories - y cuestionador Jonathan Swift escribió un ensayo crítico de las condiciones paupérrimas de Irlanda debido al colonialismo inglés.

Hubo chistes políticos durante la Revolución Francesa, sobre Napoleón y muchos otros temas candentes. Así que, en el siglo XIX, debido a la vigilancia y la censura, se produjo la aparición de la prensa clandestina en muchos países. El cabaret se convirtió en 
un eficiente medio de crítica, extendiéndose por toda Europa y, en la Alemania nazi, el humor fue empujado a la clandestinidad. Además, se destaca que el humor patibulario de los chistes (anti) nazis fue una importante forma de resistencia.

El tercer capítulo, “Humor político 'comunista”" (pp. 113 a 173), trata específicamente sobre el humor "comunista". En ese punto, el autor hace notar que los chistes políticos clandestinos eran vitales en esos países porque eran un instrumento para expresar quejas y críticas. Menciona también que la persecución por contar chistes se remonta a la Antigüedad y ya está registrada en la Grecia clásica; en la Unión Soviética era considerado como una "actividad contrarrevolucionaria".

Anekdot es la palabra rusa para "chiste político clandestino" y era una forma de desmentir la política oficial. Su tremenda popularidad, de acuerdo a Várnagy, socavó y deslegitimó al régimen soviético. Se hace referencia a la influencia del humor judío, armenio y georgiano, las diferencias entre la esfera pública y la doméstica, los chistes sobre la estupidez, y se realiza una periodización del humor político “comunista" desde la década de 1920, pasando por el estalinismo, el deshielo, la década de 1960, el centenario del nacimiento de Lenin, el estancamiento brezhneviano y los cambios producidos por Gorbachov, con ejemplos concretos de una recopilación de chistes tanto en la Unión Soviética como en todos los países de los socialismos realmente existentes en Europa.

El capítulo cuatro, “Chistes en la Unión Soviética” (pp. 175 a 273), es una colección de humor clandestino desde 1917 hasta 1991. Se cita a Karl Marx cuando éste dice que "La última fase de una forma histórica mundial es su comedia" (Introducción a la Contribución de la crítica de la Filosofía del Derecho de Hegel de 1844). Se presenta aquí una síntesis de la vida en la URSS:

¿Cómo es la vida en la Unión Soviética? Con Lenin era como estar en un túnel: rodeados de oscuridad pero con una luz adelante que nos guiaba. Con Stalin era como andar en autobús: uno conduce, algunos están sentados ["estar sentado" en ruso es sinónimo de "estar en prisión”], el resto temblando. Con Jrushchov era como estar en un circo: un hombre habla y todos los demás se ríen. Con Brezhnev era como estar en el cine con una mala película: todos 
están esperando que el espectáculo termine $y$, finalmente, Gorbachov es quien descorre las cortinas para que la gente salga.

El capítulo quinto, “Chistes en Europa central y oriental” (pp. 275 a 335), selecciona y recopila el humor prohibido de Alemania, Bulgaria, Checoslovaquia, Hungría, Polonia, Rumania y Yugoslavia. La migración del humor fue una característica de todos esos países, y el mismo chiste podía contarse sobre Ulbricht, Ceaucescu o Rákosi:

En Bucarest hay una larga fila de más de dos kilómetros para comprar pan. Uno de los posibles clientes, furioso, grita: “iVoy a matar a Ceaucescu!”, y se va corriendo. Regresa una hora después y le preguntan: “¿Lo mataste?” “No, la cola allí era más larga...".

Otro chiste, más específicamente nacional, referido a la fuerte religiosidad de los polacos y claramente subversivo, es el siguiente:

Un político francés visita Polonia. El domingo expresa su deseo de ir a misa y se le asigna un alto funcionario para que lo acompañe.

“¿Es usted católico?”, le pregunta el francés.

"Creyente, pero no practicante".

"Por supuesto, ya que usted es un comunista".

"Practicante, pero no creyente".

El último capítulo, “Humor y deslegitimación” (pp. 337 a 359), se discurre el tema de la legitimidad en la URSS y los países del bloque en Europa, donde el autor considera que los chistes reflejaban la crisis de los valores socialistas y el quebranto de su legitimidad, pues atacaban las bases y fundamentos mismos de la ideología, subvirtiendo al sistema y produciendo una inversión del mundo. Introduce aquí el pensamiento del ruso Mijaíl Bajtín, en La cultura popular en la Edad Media y en el Renacimiento. El contexto de Francois Rabelais, en que analizó el carnaval medieval y la conciencia popular, el divorcio entre el lenguaje oficial y la realidad concreta. Várnagy afirma que la incongruencia entre ambos se daba tanto en el Medioevo como en la Unión Soviética, y la naturaleza rebelde del carnaval y la risa fueron una fuerza liberadora y revolucionaria. El 
humor carnavalesco produjo la desestructuración de la cultura oficial y la deslegitimación del orden existente.

En síntesis, el autor tiene en cuenta que las tendencias centrales de los chistes apuntaban a los mismos fundamentos del sistema, abarcando un rango excepcionalmente amplio, desde aspectos de la vida cotidiana hasta los eventos políticos más importantes. Los chistes fueron una respuesta integral a todo el cuerpo doctrinario, desacreditando el carácter científico de la teoría y la práctica, y revelando la traición al pensamiento de los fundadores, lo que produjo una pérdida de legitimidad que subvirtió todo el esquema del bloque soviético.

El libro es un trabajo sumamente original, exhaustivo en el análisis del tema, con recopilación de materiales inexistentes en lengua española $y$, por momentos, tan divertido que resulta imposible no soltar una risa franca. Además, contiene una importante bibliografía (pp. 361 a 372) en varios idiomas y más de 80 ilustraciones poco conocidas (fotos, afiches y caricaturas).

Tomás Várnagy, húngaro-argentino, es profesor de Filosofía, doctor en Ciencias Sociales y enseña Teoría Política en la Universidad de Buenos Aires.

Recebido em 08/05/2016 Aprovado em 18/06/2016

Universidade do Estado de Santa Catarina - UDESC Programa de Pós-Graduação em História - PPGH

Revista Tempo e Argumento Volume 08 - Número 18 - Ano 2016 tempoeargumento@gmail.com 